\title{
Measurement of Radon Concentration of Air Samples and Estimating Radiation Dose from Radon in SARI Province
}

\author{
Seyed Ali Rahimi", Behzad Nikpour \\ Faculty of Health, Mazandaran University of Medical Sciences, Kilometer 18 KHAZARABAD Road, SARI, Iran \\ *Corresponding Author: rahimi201@yahoo.com
}

Copyright (C) 2013 Horizon Research Publishing All rights reserved.

\begin{abstract}
Exposure to radon is the second leading cause of lung cancer after smoking. Radon is an odorless, tasteless and invisible gas produced by the decay of naturally occurring uranium in soil and water. The amount of radon in the air is measured in "picocuries per liter of air," or "pCi/L." There are many kinds of low-cost "do-it-yourself" radon test kits you can get through the mail and in some hardware stores and other retail outlets. In this study to measure radon in homes in the province of Sari by dosimeters DOSEman (SARAD GmbH company). Population of the city of Sari 495,369 people and the urban population of village of forty to sixty is the degree of concentration of 116.5 people/ $\mathrm{km}^{2}$. A percentage of the total household population of Sari in areas geographically different samples is selected. Radon measuring in four different seasons (in one year) at home for sampling was done. Sensors 60 -minute room bedroom or living at an altitude of 50 to $90 \mathrm{~cm}$ from the floor, away from windows and sunlight placed howe dose rate and radon gas in homes has been measured. Amount of radon in your home in spring 28.615Bq m-3, in summer Bq m-3 27.20, in autumn 27.07Bq m-3 in winter Bq m-3 36.95 measures. Both dose levels in spring $.0032 \mu \mathrm{Sv}$, in the summer $0.026 \mu \mathrm{Sv}$, in the autumn $0.037 \mu \mathrm{Sv}$ in winter $0.056 \mu \mathrm{Sv}$ is measured. Annual dose equivalent to approximately $0.0151 \mu \mathrm{Sv}$ / year .Radon measurement results show that the average radon concentration is higher in winter than other seasons. This difference could be due to lack of air movement and stillness, and the dose of radon indoors in winter.
\end{abstract}

Keywords Natural Radioactivity, Radon, Lung Cancer, Radiation Dose, SARI Province

\section{Introduction}

Exposure to radon is the second leading cause of lung cancer after smoking. Radon is an odorless, tasteless and invisible gas produced by the decay of naturally occurring uranium in soil and water. Radon is a form of ionizing radiation and a proven carcinogen. Lung cancer is the only known effect on human health from exposure to radon in air.
Radon is found in outdoor air and in the indoor air of buildings of all kinds. EPA recommends homes be fixed if the radon level is $4 \mathrm{pCi} / \mathrm{L}$ (picocuries per liter) or more.

Because there is no known safe level of exposure to radon, EPA also recommends that Americans consider fixing their home for radon levels between $2 \mathrm{pCi} / \mathrm{L}$ and $4 \mathrm{pCi} / \mathrm{L}(1,2)$.

The average radon concentration in the indoor air of America's homes is about $1.3 \mathrm{pCi} / \mathrm{L}$. It is upon this level that EPA (United States Environmental Protection Agency) based its estimate of 20,000 radon-related lung cancers a year upon. While a smoker has a 20 in 1,000 chance of dying from lung cancer $(1,2)$. Compares the It is for this simple reason that EPA recommends that Americans consider fixing their homes when the radon level is between $2 \mathrm{pCi} / \mathrm{L}$ and $4 \mathrm{pCi} / \mathrm{L}$ for this population about 62 people in a 1,000 will die of lung-cancer, compared to the average concentration of radon in outdoor air is $4 \mathrm{pCi} / \mathrm{L}$ or $1 / 10$ th of EPA's $4 \mathrm{pCi} / \mathrm{L}$ action level. For smokers the risk of lung cancer is significant due to the synergistic effects of radon and smoking. 7.3 people in a 1,000 for never smokers. Put $\mathrm{pCi} / \mathrm{L}$ the risk to smokers is six times the higher risk than never smokers, e.g., at another way, a person who never smoked (never smoker) who is exposed to $1.3 \mathrm{pCi} / \mathrm{L}$ has a 2 in 1,000 chance of lung cancer; risks between smokers and never smokers; smokers are at a much risk to never smokers. Figure 1 Effect of radon daughters in human lung is shown.

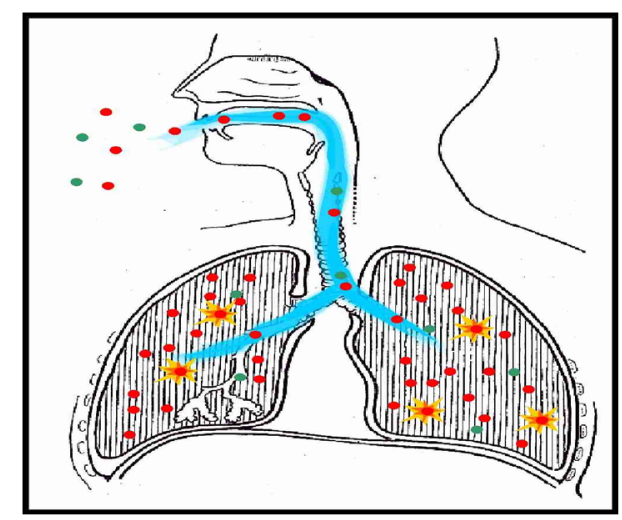

Figure 1. Dangerous Impact of Radon Daughters

Directly after the decay, the remaining Po-218 nuclei 
become charged positively for a short period, because some shell electrons are scattered away by the emitted alpha particle. Those ions are collected by the electrical field forces on the surface of a semiconductor detector. The number of collected Po-218 ions is proportional to the Radon gas concentration inside the chamber. Po-218 itself decays with a half life time of only 3.05 Minutes and about $50 \%$ (particles emitted towards the detector surface) of all decays will be registered by the detector. The equilibrium between the Radon decay rate and Po-218 detector activity is given after about 5 half life times, say 15 minutes.

This time span defines the minimum achievable response time to a Radon concentration step $(1,2$, and 20).

Now, the decay chain is continued by the both beta emitters $\mathrm{Pb}-214$ and $\mathrm{Bi}-214$ followed by another alpha emitter, the Po-214. That means, each Po-218 decay causes one more detectable decay by the Po-214 which is delayed about 3 hours because of the superposed half life times of those nuclides. The emission energies of Po-218 and Po-214 are different and therefore it is possible to separate both nuclides from each other by alpha spectroscopy $(3,4,20)$.

Spectroscopic working monitors offer two calculation modes for the Radon concentration, one (Slow) includes both, Po-218 and Po-214 decays and the other one includes Po-218 only (Fast).

The advantage of the "Fast" mode is the quick response to concentration changes. while the "Slow" mode gives sensitivity twice as high compared with the fast mode.

The higher sensitivity reduces the statistical error of a measurement which depends on the number of counted decay events only. The user should select the calculation mode carefully with respect to the application specific requirements (see next chapter). In case of Thoron (Rn-220), the direct daughter product Po-216 (which also underlies the ionization process) is used to calculate the Thoron activity concentration. The half life of Po-216 is less than 1s and therefore the equilibrium state between gas concentration and collected activity on the detector is present immediately. The half life of the Po-216 decay products $\mathrm{Pb}-212$ (beta) and $\mathrm{Pb}-212 / \mathrm{Bi}-212$ (alpha) are too long to use them for Thoron measurement. The single nuclides of the Thoron decay chain will also separated by alpha spectroscopy $(5,6$, and 20$)$.

In particular, radon has been recognized as a hazard to underground miners for many years. At present, the possibility that radon may be a significant hazard in living environments is a worldwide concern. Since the potential risk from residential exposures to radon is of great interest in many countries, evaluation methods to determine the risk from exposure to residential radon are needed. Epidemiological studies of underground miners provide the basis for estimating risks from residential exposures to radon and its decay products by extrapolating the results of miner studies downward to nowadays, the methods of estimating dose of inhaled decay products of short half-life

exposure levels seen in homes $(2,10)$. The estimation of exposure conditions is often required in the miner studies many years back in time. Since there are few or no actual exposure measurements, however, the results from such studies may be uncertain. Many additional assumptions are needed when risks estimated in miner studies are extrapolated to residential exposure conditions $(3,10)$.Taking these circumstances into account, there has been great interest in developing direct estimates of residential risk for the general population using case-control studies. The environmental conditions in mines and homes are quite different. For a precise evaluation of radon exposures, the contribution of Thoron should be considered if the radon level is low in homes. Its presence often results in misleading estimation of radon concentrations. Before conducting a case-control study on residential radon exposures, it is important to understand those characteristics in the study area (10).

It is found everywhere including indoor atmosphere that is breathed into the lungs out. If high concentrations of radon gas in homes can cause lung cancer. Exposures arising from the inhalation of radon gas in homes are much higher than other radiation exposures arising from normal new sets. Radioactive materials generally have direct effects on cells. These effects include:

Than the effects reviewed and the International Commission on Radiation Protection (ICRP) Tissue weighting coefficients and coefficients of radon effective dose of radiation to define which can lead to abnormal cells. It is involved in diseases such as cancer of treatment for cancer and eliminates cancer cells used $(6,7)$. Given the importance of research being done about it. Sari Province the aim of this study was to measure radon in homes and residents in the city of Sari is the dose $(8,9$, and 10).

\section{Materials and Methods}

The present survey was conducted in SARI Province. Based on previous studies of radon exposure will be measured in different seasons of the year. Sari province, north of the Caspian Sea, south of Alboroz Mountains, east and west cities of Neka and Behshahr city Ghaemshahr leads. The sari has an area of $3923 \mathrm{~km}$ in longitude 53 degrees 59 minutes and latitude 36 degrees 50 minutes.

Sari province has 15 districts, 4 cities (Sari, Kiasar, Frames, Sorak) and 4 parts Chahardangeh area 1512.6 square kilometers, Dodangeh the Area 588.2 square kilometers of the central area of $1167.3 \mathrm{~km}^{2}$, Klijan Rustaq and Miyandorud area $435.8 \mathrm{Km}^{2}$. Sari population of 261,293 people and is considered the largest and most populous city of the province of Sari city of 495,369 people, and the urban population of the village is forty to sixty degrees of density 116.5 people per square kilometer. Based on studies and research projects have been conducted in other parts of the world and other Iranian city of Sari one percent of homes in different geographic areas for sampling were selected (2600 time samples according to the latest census data Sari province population).

In Figure 2 the device used to measure radon levels and absorbed dose is shown: 


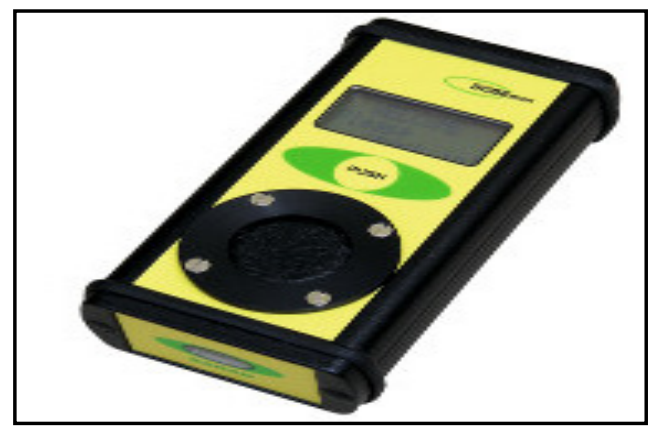

Figure 2. The DOSEman was developed as a personal Radon dosimeter within a project of the German Federal Office of Radiation Protection. The small outlines, the light weight and its roughness allowing a stress-free permanent wearing of the instrument.

With regard to the measurement of radon in homes in four seasons a year that will be selected for sampling, houses to form physical change or change in its internal structure is established are excluded from the sample. To take samples (woman and man) have the necessary training to residents (houses the city according to the geological map of Sari province generation light sources are radon) detectors lack of transport and lack of open doors and windows in the room where the detector is presented during the 60 minute sampling. Sensors bedroom or living room for 60 minutes and at a height of 50 to $90 \mathrm{~cm}$ from the floor away from the windows and the sun has set $\mu \mathrm{Sv} /$ year is determined.

\section{Results and Discussion}

The study was conducted in two states, Shanxi and Shaanxi, China in 2003 to measure gases, Radon and Thorne was the mean value of radon gas in the two states are listed in order of $46 \mathrm{~Bq} / \mathrm{L}$ and $70 \mathrm{~Bq} / \mathrm{L}$ have been reported $(11,12$, 13).

The report measured radon levels in summer and winter respectively $25.1 \mathrm{~Bq} / \mathrm{L}$ and $152 \mathrm{~Bq} / \mathrm{L}$ and the dose for residents of Hamadan stay indoors in winter to a maximum of 10 hours $1.44 \mathrm{mSv}$ and for the summer season with $0.2 \mathrm{mSv}$ was calculated $(14,15)$. Radon measurement results show that the average concentration of radon gas in the city of Sari in the winter than the other seasons (Table 2 and 3 and 4). Accordingly, the dose is higher in winter than other seasons (Table 5 and 6 and 7). This difference could be due to lack of airflow and radon indoors in winter is stillness (16, 17). In Figure 3 and the effects of radon gas cycle is shown. due to the lack of natural ventilation or mechanical man-made and well above the doors and windows are closed. Resulting in high levels of radon can cause lung cancer. Sari province of radon concentration measurements in comparison to the state average radon concentration in the houses of the US and China and Mashhad city and city of Hamadan in Iran and the international standard (average radon concentration in air of approximately $0.4 \mathrm{PCi}$ is lower (18). In cold climates to keep warm, open houses are closed; radon can penetrate the cracks in the floor. In these areas, buildings with basements, open floors are recommended. This risk is lower in environments that have proper ventilation $(19,20)$. Table 1 about exposure to radon gas in the U.S., Europe and China are listed $(21,22)$.The standard reference values specified in the table (23). Figure 4 Map of Radon measure absorbed dose to the northern city of Sari in Iran is shown. Figure 5 Sources of radon gas and its distribution is shown in the homes of residents $(24,25)$.

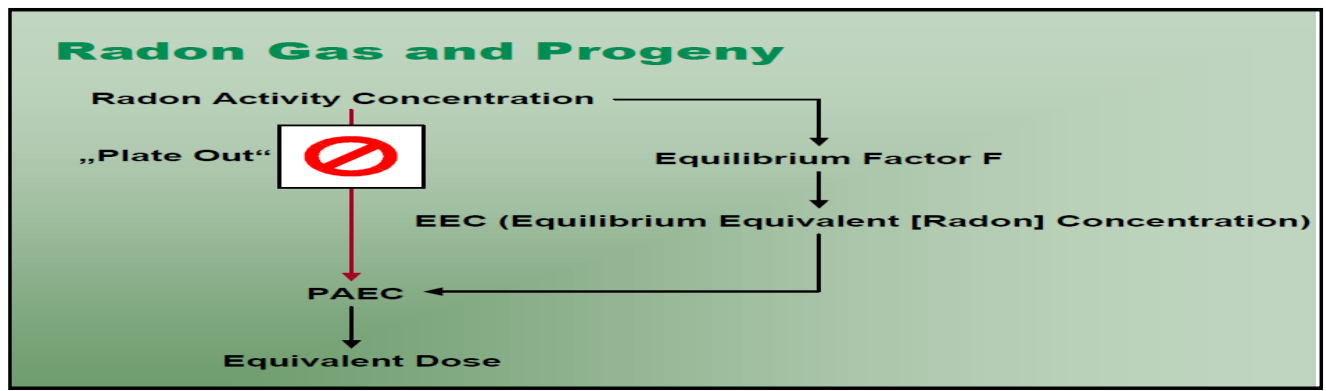

Figure 3. Radon Gas and Progeny (SARAD GmbH)

Table 1. International Limits for Radon Exposure (SARAD GmbH)

\begin{tabular}{|c|c|c|}
\hline & Dwellings & Workplaces \\
\hline EU & $\begin{array}{c}200 \mathrm{~Bq} / \mathrm{m}^{3} \text { (buildings under construction) } \\
400 \mathrm{~Bq} / \mathrm{m}^{3} \text { (existing buildings) }\end{array}$ & $6 * 10^{6} \mathrm{Bqh} / \mathrm{m}^{3}(\mathrm{WLM})$ \\
\hline P.R.China & $200 \mathrm{~Bq} / \mathrm{m}^{3}$ & \\
\hline United States & $4 \mathrm{pCi} / \mathrm{L}=150 \mathrm{~Bq} / \mathrm{m}^{3}(\mathrm{EPA})$ & 4 WLM (DOE,EPA) \\
\hline ICRP & $200 \ldots 600 \mathrm{~Bq} / \mathrm{m}^{3}(1993)$ & 4 WLM (1994) \\
\hline
\end{tabular}


Table 2. Average radon concentrations at seasons

\begin{tabular}{|c|c|c|}
\hline Number of households in different geographical areas & season & $\begin{array}{c}\text { Radon } \\
(\mathrm{Bq} \mathrm{m}-3)\end{array}$ \\
\hline 650 & Spring & 28.615 \\
\hline 650 & Summer & 27.20 \\
\hline 650 & Autumn & 36.95 \\
\hline
\end{tabular}

Table 3. Average dose inhabitant's at seasons

\begin{tabular}{|c|c|c|}
\hline Number of households in different geographical areas & season & DOSE $(\mu \mathrm{Sv})$ \\
\hline 650 & Spring & 0.032 \\
\hline 650 & Summer & 0.037 \\
\hline 650 & Autumn & 0.056 \\
\hline 60 & Winter & . \\
\hline
\end{tabular}

Table 4. Average PO-218 at seasons

\begin{tabular}{|c|c|c|}
\hline Number of households in different geographical areas & season & 28.63 \\
\hline 650 & Spring & 27.47 \\
\hline 650 & Summer & 27.07 \\
\hline 650 & Autumn & 35.22 \\
\hline
\end{tabular}

Table 5. Average PAEC (Potential Alpha Energy Concentration of any Progeny mixture in Air) at seasons

\begin{tabular}{|c|c|c|}
\hline Number of households in different geographical areas & season & 27.05 \\
\hline 650 & Spring & 18.81 \\
\hline 650 & Summer & 26.44 \\
\hline 650 & Autumn & 36.16 \\
\hline
\end{tabular}

Table 6. Average EEC (Equilibrium Equivalent (Radon) Concentration) at seasons

\begin{tabular}{|c|c|c|}
\hline Number of households in different geographical areas & season & EEC \\
\hline 650 & Spring & 3.21 \\
\hline 650 & Summer & 4.10 \\
\hline 650 & Autumn & 4.57 \\
\hline 650 & Winter & 6.67 \\
\hline
\end{tabular}


Table 7. Average PAEE (Potential Alpha Energy Exposure) at seasons

\begin{tabular}{|c|c|c|}
\hline Number of households in different geographical areas & season & PAEE \\
\hline 650 & Spring & 28.76 \\
\hline 650 & Summer & 18.92 \\
\hline 650 & Autumn & 27.05 \\
\hline 650 & Winter & 38.2 \\
\hline
\end{tabular}

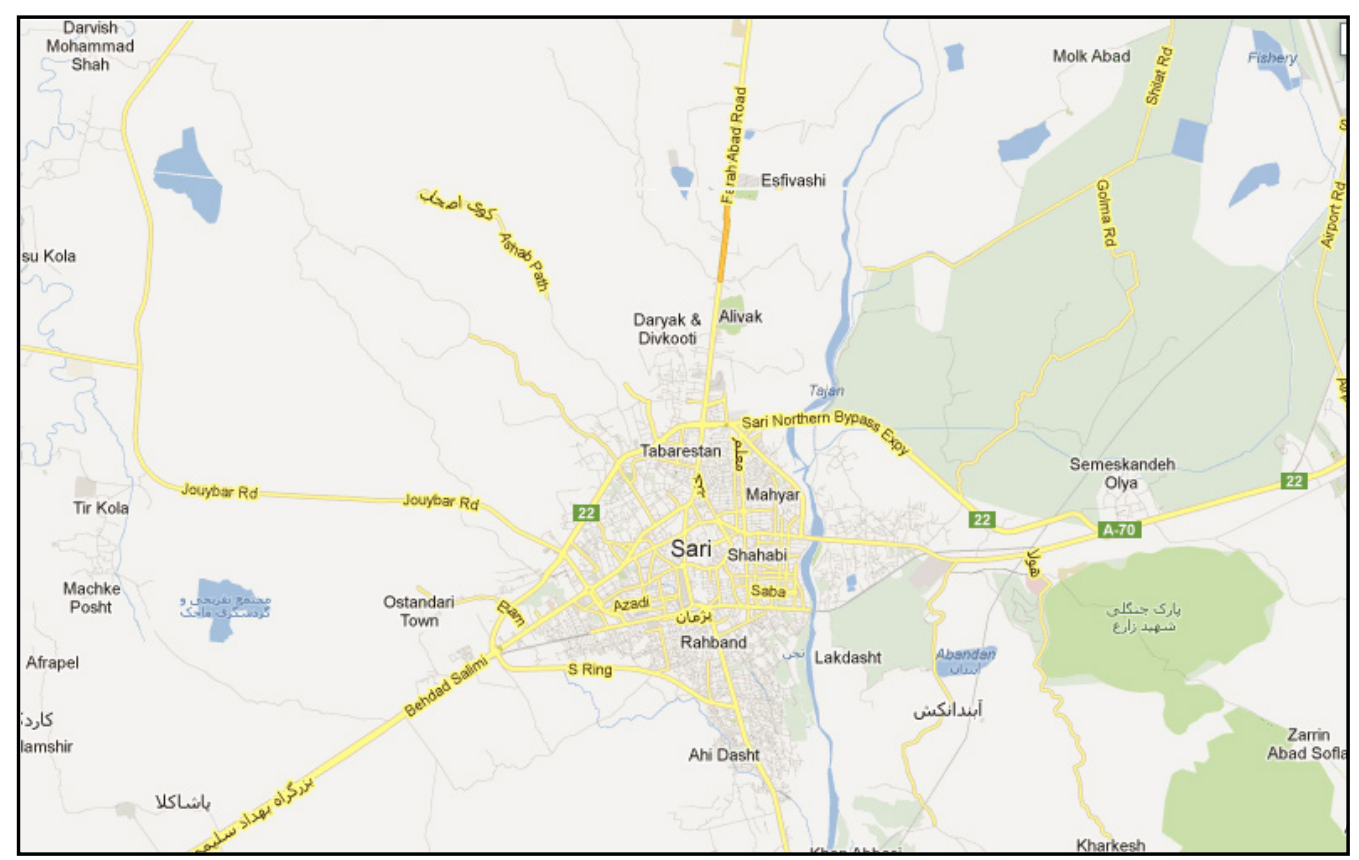

Figure 4. Map of the study area (SARI Province)

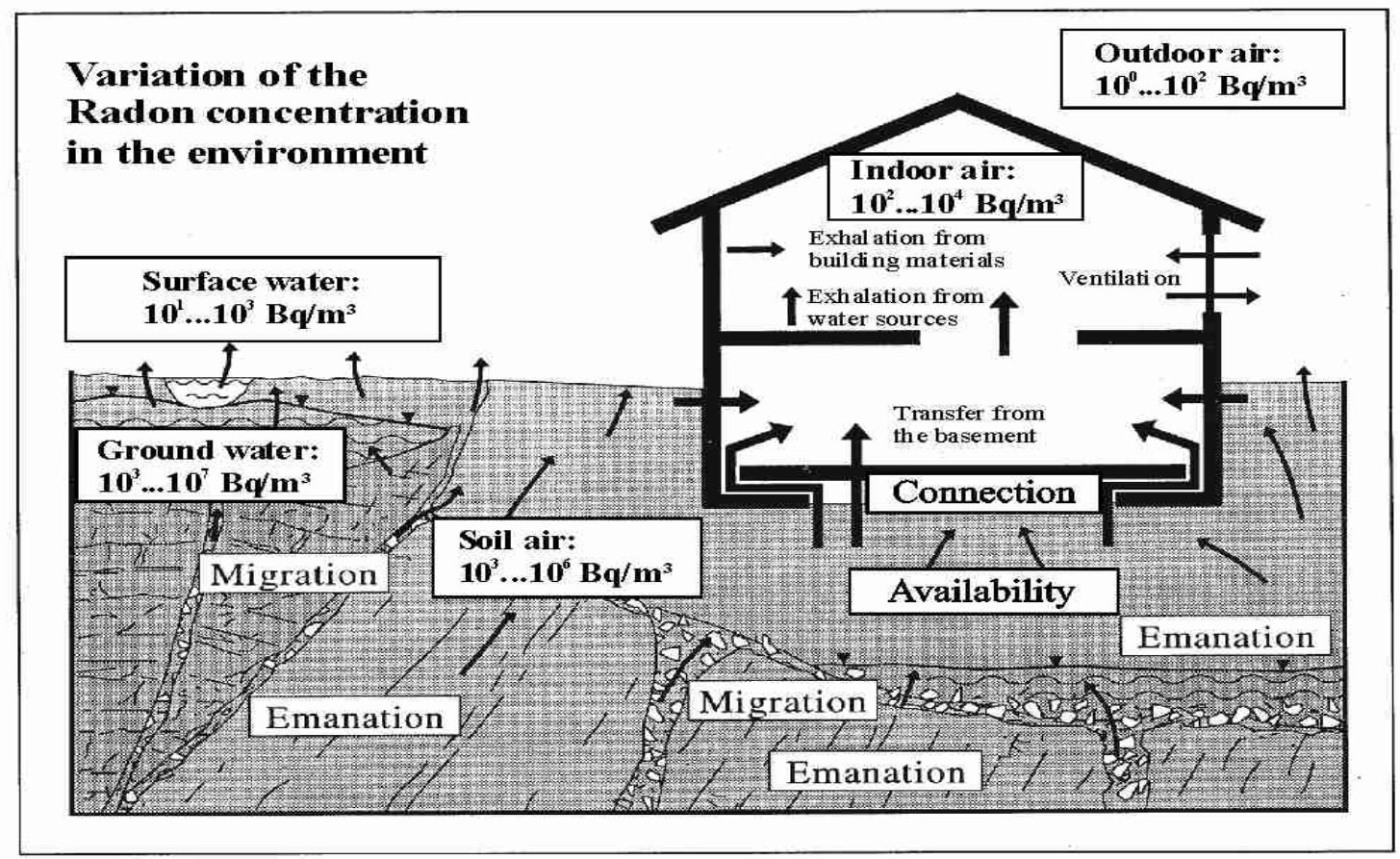

Figure 5. Radon Origin and Distribution (SARAD GmbH) 


\section{Acknowledgment}

This study was financially supported by the research deputy of Mazandaran University of Medical Science.

\section{REFERENCES}

[1] http://www.epa.gov/radon/pubs/citguide.html\#howtotest

[2] Building Radon Resistant Foundations - A Design Handbook, NCMA, 2002.

[3] Council of American Building Officials (CABO) Model Energy Code, 2002.

[4] Energy Efficient Design of New Buildings Except Low-Rise Residential Buildings, ASHRAE Standard 90.1-2002.

[5] Energy Efficient Design of New Low-Rise Residential Buildings, Draft ASHRAE Standard 90.2 (Under public review), 2003.

[6] Indoor Radon and Radon Decay Product Measurement Device Protocols. EPA 402-R-92-004, July, 2004.

[7] Protocols for Radon and Radon Decay Product Measurements in Homes. EPA 402-R-92-003, June, 2005.

[8] Radon Control Options for the Design and Construction of New Low-Rise Residential Buildings, ASTM Standard Guide, E1465-92, 2006.

[9] Radon Resistant Construction Techniques for New Residential Construction. Technical Guidance. EPA/625/2-91/032, February, 2007.

[10] Radon and Thoron Exposures for cave residents in Shanxi and Shaanxi Provinces. Shinji Tokonami and etal . Radiation Research Journal, 162,390-396(2004).

[11] Evaluation of absorbed dose from radon and its staff and visitors Gharlysdr Hamedan, 2007. Conference humans, light, live .1385; Rafsanjan - Iran, Joiner Jabari MN, Gavin Gilmore, H. Samavat, G. Azizian.
[12] Evaluation of absorbed dose from radon and its residents Hamadan, 2009. Conference humans, light, live .2009; Rafsanjan - Iran, Joiner Jabari MN, Gavin Gilmore, H. Samavat.

[13] Sadat Mohammad Javad, sympathy graduate student in nuclear engineering, AEOI and measurement of radon and radon dosimeter sensitivity of Mashhad, '2010 residential homes.

[14] Pisa FE, Barbone F, Betta A, et al. Residential radon and risk of lung cancer in an Italian alpine area. Arch Environ Health. A Cancer Journal for Clinicians, 2001; 56:208-215. (This information is current as of April 4, 2009).

[15] BEIR, Health effects of exposure to low levels of ionizing radiation, National Academy Press, Washington D.C. (1990), BEIR V, Committee on the Biological Effects of Ionizing Radiations.

[16] BEIR, Health effects of exposure to Radon, National Academy Press, Washington D.C. (1999), BEIR VI, Committee on Health Risks of Exposure to Radon.

[17] BEIR, Health effects of Radon and other internally deposited alpha-emitters, National Academy Press, Washington D.C. (1988), BEIR IV, Committee on the Biological Effects of Ionizing Radiations.

[18] R. Doll et al., Mortality in relation to smoking: 40 years observations on male British doctors, BMJ, (1994), vol. 309, pp. 901-911.

[19] J.H. Lubin, J.D. Boice, C. Edling et al., Radon and lung cancer risk: A joint analysis of 11 underground miners studies, NIH, Washington DC, (1994), Publication No. 94-3644.

[20] SARAD GmbH AN-002_MeasurementPrincipals-Statistics-TestPlanning_E N_09-05-12, www.sarad.de.

[21] Zastawny A, Kwasniewicz E, Rabsztyn B (1979) Measurement of the $232 \mathrm{Th}, 238 \mathrm{U}$ and $40 \mathrm{~K}$ concentration in some samples of ashes from power stations in Poland. Nukleonika, 24: 535 